Bond University

Research Repository

\title{
A biomechanical analysis of the strongman log lift and comparison with weightlifting's clean and jerk
}

Winwood, Paul W.; Cronin, John B.; Brown, Scott R.; Keogh, Justin W. L.

Published in:

International Journal of Sports Science and Coaching

DOI:

10.1260/1747-9541.10.5.869

Licence:

Other

Link to output in Bond University research repository.

Recommended citation(APA):

Winwood, P. W., Cronin, J. B., Brown, S. R., \& Keogh, J. W. L. (2015). A biomechanical analysis of the

strongman log lift and comparison with weightlifting's clean and jerk. International Journal of Sports Science and Coaching, 10(5), 869-886. https://doi.org/10.1260/1747-9541.10.5.869

\section{General rights}

Copyright and moral rights for the publications made accessible in the public portal are retained by the authors and/or other copyright owners and it is a condition of accessing publications that users recognise and abide by the legal requirements associated with these rights.

For more information, or if you believe that this document breaches copyright, please contact the Bond University research repository coordinator 
Title: A Biomechanical Analysis of the Strongman Log Lift and Comparison with

\section{Weightlifting's Clean and Jerk}

Paul W. Winwood ${ }^{1,2}$., John B. Cronin, ${ }^{1,3}$., Scott R. Brown, ${ }^{1}$., and Justin W. L. Keogh, ${ }^{1,4,5}$.

${ }^{1}$ AUT University' Sport Performance Research Institute New Zealand' School of Sport and Recreation, Auckland, New Zealand

${ }^{2}$ Bay of Plenty Polytechnic, School of Applied Science, Tauranga, New Zealand

${ }^{3}$ Edith Cowan University, School of Biomedical and Health Sciences, Perth, Australia

${ }^{4}$ Bond University, Faculty of Health Sciences and Medicine, Gold Coast, Australia

${ }^{5}$ University of the Sunshine Coast, Cluster for Health Improvement, Faculty of Science, Health, Education and Engineering, Queensland, Australia 


\section{ABSTRACT}

This study compared the biomechanical characteristics of the log lift and clean and jerk. Six experienced male strongman athletes performed log lifts and clean and jerks at $70 \%$ of their $1 \mathrm{RM}$ clean and jerk. Significant $(\mathrm{P}<0.05)$ between-exercise kinematic differences were observed throughout all the lifting phases, except at lift completion. The log lift demonstrated significantly greater trunk ( $\uparrow 24 \%)$ and hip $(\uparrow 9 \%)$ range of motion than the clean and jerk. Significantly greater peak bar velocities were achieved in the clean and jerk in the second pull $(\uparrow 16 \%)$ and the jerk $(\uparrow 14 \%)$. While similarities existed in ground reaction force data between the lifts, mean and peak powers were significantly greater $(\uparrow 40 \%$ to $\uparrow 64 \%)$ in propulsive phases of the clean and jerk. The log lift may be an effective conditioning stimulus to teach rapid triple extension while generating similar vertical and anterior-propulsive forces as the clean and jerk with the same given load.

Keywords: Biomechanics, kinematics; kinetics; strongman; resistance training 


\section{INTRODUCTION}

Strongman is a sport similar to weightlifting, bodybuilding and powerlifting in which weight training is the primary form of training [1]. The log lift (known as the king of overhead lifts) is a popular strongman event performed by strongman athletes both in training and competition [1]. The event requires athletes to lift the log off the ground and raise it above the head with elbows and knees extended. The log lift performed at strongman events can range from maximal strength (i.e. 1RM lifts) events to strength endurance events with athletes performing as many repetitions as possible in a specified time, generally $60-90$ seconds with a specified load. Since the log lift consists of cleaning the log from the ground and pressing it overhead, it is deemed to be a functional strength and conditioning exercise because of the increased need for total body stabilisation [2].

The log lift would appear similar to the clean and jerk but is performed with a neutral grip, which may help decrease the risk of shoulder injury as the hands and elbows are more anterior to the shoulder $[3,4]$. Similar to the weightlifting movements, the log lift typically involves forceful triple extension at the ankle, knee and hip, which is biomechanically similar to movements found in a variety of sports [5-7]. The log lift, as with the weightlifting exercises requires rapid acceleration of the resistance that occurs with no intention to decelerate the resistance at the end of the range of motion. Thus, the log lift, from a biomechanical perspective may be an excellent method to train high-load total-body speed strength.

The log lift may have some advantages over traditional weightlifting movements. Weightlifting movements such as the clean and jerk are very complex and contain a high degree of technical difficulty [8]. Unlike the clean and jerk, the log lift contains two retrieve phases. In the first retrieve lifters lift the log onto the thighs after the first pull and then 
prepare for the second pull by squatting down with the log resting on the thighs. The squat position allows the lifter to position the log where forceful hip, knee and ankle extension can be used to roll the log up the body into the second retrieve. Since the log can be rested on and rolled up the body, the log lift may be less technically demanding than weightlifting movements. The log lift may therefore be seen as possible alternative or as a regression from the clean and jerk for strength and conditioning coaches wanting to improve athlete's strength and power development. Recently researchers [9] reported that $88 \%(\mathrm{n}=193)$ of strength and conditioning coaches used strongman implements in the training of their athletes with the steel logs ranked the ninth most common implement used by coaches.

To date, very few studies have investigated the strongman log lift. Studies have investigated how strongman competitors train [1] and the injury epidemiology associated with strongman training [10]. While these studies provided valuable insight into how strongman athletes train with the $\log$ (e.g. reps, sets, loads etc) and the sites of injuries associated with performing log lifts, no biomechanical studies have investigated the log lift. Since the log lift is now being used in strength and conditioning practice as a means of performance enhancement, it is important for practitioners to understand the kinematics and kinetics of this event to better appreciate the potential stresses this event places on the body. Such data would give practitioners a greater understanding of the acute stresses that the log lift imposes on the system and the likely chronic adaptations to this form of training. Therefore the purpose of this study was to examine the kinetic and kinematic characteristics of the log lift and make comparisons with the clean and jerk, as the clean and jerk is a common weightlifting exercise used by strength and conditioning coaches to enhance total body strength and power and is comparable to the movements associated with the log lift. Such an analysis is analogous to recently published papers by Winwood and colleagues $[11,12]$ comparing strongman events to similar traditional exercises. These types of studies may also help equate loading and time 
under tension in future training studies wishing to compare exercises such as log lift pull versus the clean and jerk on aspects of muscular function and performance. It was hypothesised that the log lift would show similar kinetic characteristics to the clean and jerk but kinematic differences would exist between the lifts. It was surmised that the diameter of the log, being much larger than a standard Olympic barbell, would change lifting kinematics because the log cannot be kept as close to the body as that of a traditional barbell.

\section{METHODS}

\section{EXPERIMENTAL APPROACH TO THE PROBLEM}

A cross-sectional descriptive design was used to quantify and compare the kinematics and kinetics of the log lift and clean and jerk. The participants were well-trained strongman athletes with extensive experience performing the traditional and strongman lifts. Data were collected for each participant over two sessions separated by one week. Session 1 was performed in the strength and conditioning laboratory and involved 1-repetition maximum $(1 \mathrm{RM})$ testing in the clean and jerk. Session 2 was performed in the biomechanics laboratory where participants performed repetitions in the clean and jerk and log lift (respectively) on force plates using loads of $70 \% 1 \mathrm{RM}$. Kinematics and ground reaction force kinetics were recorded during the second session. Note: Strongman participants in this study also completed other traditional and strongman lifts (deadlift, farmers walk, squat and heavy sled pull, respectively) in the testing session after the clean and jerk and log lift were performed (respectively), and these appear as separate publications within the International Journal of Sport Science and Coaching $[11,12]$. While multiple lifts were performed in the training sessions, participants performed only 2 to 3 repetitions for each exercise and long rest periods were given between exercises to minimise any effects on subsequent lifting performance. This testing session was also based on common training practices whereby strongman 
athletes typically perform multiple exercises within a given training session, with moderately long rest periods between exercises [1].

\section{PARTICIPANTS}

Six male strongman athletes (four national and two regional level athletes) volunteered to participate in this study, a summary of the participant's characteristics are presented in Table 1. All participants regularly performed $1 \mathrm{RM}$ testing as part of their training and had an extensive strength training background; including experience with the squat, deadlift, clean and jerk and strongman events including the log lift. The study was conducted two weeks before a regional strongman competition, where the majority of athletes were at the end of a training cycle aimed at improving their previous competition performance. To be eligible to participate in this study the strongman athletes had to have at least 2-years of strongman training experience, competed in at least one strongman competition and be injury free. Prior to participation, all aspects of the research were verbally explained to each participant, written informed consent was obtained and a coded number was assigned to each participant to ensure the data remained anonymous. Full ethical approval was granted for all procedures used in this study by the Auckland University of Technology Ethics Committee (12/311).

\section{ONE-REPETITION MAXIMUM TESTING}

No supportive aids beyond the use of a weightlifting belt and chalk were permitted during the test. The warm up, loading increments and rest periods used were according to previously established protocols [13]. Maximum strength was assessed by a 1RM performed with a free-weight Olympic-style barbell. Completed lifts in the clean and jerk were recognised when the participants were standing still with feet shoulder width apart, the knees and elbows extended and the bar or log overhead. Note: The rules for the clean and jerk were somewhat lenient as a press-out (whereby the athlete could not lockout the elbows completely on initial 
press attempt) was allowed given the fact that the athletes were experienced strongman athletes rather than experienced weightlifters.

\section{TRADITIONAL AND STRONGMAN TESTING}

Before performing the lifts, participants engaged in a self-selected total body dynamic warmup similar to their specific weight training and competition warm-up procedures. Generally this began with two light sets of each lift (e.g., <40\%1RM) for 6-10 repetitions. All the participants then performed testing loads of each exercise before any data collection. Once suitably prepared, the participants performed a trial of the exercise to commence with a load of $70 \% 1 \mathrm{RM}$. Loading for the $\log$ lift $(\log 58.1 \mathrm{~kg}$, length $2355 \mathrm{~mm}$, diameter $165 \mathrm{~mm}$, handle thickness of $33 \mathrm{~mm}$ diameter, Getstrength, Auckland) was determined by the participants $70 \% 1 \mathrm{RM}$ clean and jerk. Participants were asked to perform the clean and jerk and $\log$ lift as explosively as possible. The 70\%1RM load was chosen for analysis as it is a load regularly used by strongman athletes [1] and in weightlifting programme design [14, 15], therefore most relevant for comparing and contrasting the two lifts.

Participants could choose any technique they wished for the log lift (spilt jerk or push press) providing that, for a repetition to be counted, it had to start from the floor and required the participant to be standing upright with feet together and knees locked and elbows extended overhead. The push press and push jerk were used by two of the participants for both the clean and jerk and log lift. All participants used the power clean technique for the clean and jerk with the $70 \% 1 \mathrm{RM}$ load. The lifts were performed in a consecutive order (clean and jerk and $\log$ lift). Participants were allocated a two minute rest period between trials. A longer rest period of up to five minutes was available between trials if the subject felt fatigued. Consistent verbal encouragement was provided during testing sessions with the participants 
frequently reminded to perform the lifts as fast as possible. Shoes worn by participants during testing were those that were typically worn in their strongman training.

\section{INSTRUMENTATION}

Twelve markers were bilaterally placed over the base of the third metatarsal, lateral malleoli, lateral femoral condyles, greater trochanter, anterior superior iliac spine, and superior boarder of the acromion process. Two Sony (HDR - CX 190E) cameras (Tokyo, Japan) were used to track the coordinates of reflective markers, adhered to the body, during the various trials at a sample rate of $60 \mathrm{~Hz}$. A Bertec force plate (Model AM6501, Bertec Corp., Columbus, OH, USA) was used to collect synchronized ground reaction forces at $1000 \mathrm{~Hz}$. A diagrammatic representation of the 2 cameras and force platform set-up is presented in Figure 1. Cameras were positioned approximately $4 \mathrm{~m}$ in front of the force platform and $3 \mathrm{~m}$ to the side of the force platform. Vicon Nexus (Version 1.8.1, Vicon Inc., Denver, CO, USA) was used to process the ground reaction force data and bar path trajectories. Ground reaction force data and bar path trajectories were filtered using fourth order low-pass digital Butterworth filters with cut-off frequencies of $300 \mathrm{~Hz}$ and $6 \mathrm{~Hz}$ (respectively) [16].

Insert Figure 1 about here

\section{DATA ANALYSIS}

Four segment/joint angles (trunk, hip, knee and ankle) variables were calculated in the clean and jerk and log lift. These angles were recorded at lift off (LO), top of first pull (TFP), start of second pull (SSP), middle of the second pull at maximum point of planterflexion, (MSP), top retrieve (point at which bar or log touches top of chest) (TR), bottom of dip and drive (BDD) and at lift completion (LC) (see Figure 2). These events were adapted for this study from those previously depicted for the clean and jerk [17]. The internal hip, knee and ankle angles (joint angles) were measured along with the trunk angle in relation to the horizontal 
axis (see Figure 2). A general measure of the range of motion (ROM) of these joint/segments was obtained by subtracting the angle at lift completion from that at initial lift off. 2D kinematics for the trunk, hip, knee and ankle angles were calculated for the right side and were analysed in Kinovea (version 0.8.15, www.kinovea.org) Intra-rater reliability of Kinovea for determining similar lower body joint angles has been shown to be high (ICC = $0.96-0.99$; typical error $1-2^{\circ}$ ) [18]. Force data and bar/log vertical and horizontal displacements were normalised for time using ensemble averaging in Microsoft Excel 2007. Bar path trajectories were presented by plotting vertical against horizontal displacements from the initial bar/log starting point. Peak and mean bar/log vertical velocities were calculated for the first pull, second pull and jerk/press. 'Dip-depth' during the jerk/push press was calculated as the distance the bar descended after top retrieve (i.e. lifter was standing stationary in a bilateral stance with bar/log on chest) to the bottom of the dip and drive. Peak power was identified as the highest instantaneous value during the propulsion phases of the first pull, second pull and jerk/push-press, whereas mean power was obtained by averaging power over each propulsive phase. The propulsive phases were identified from the velocitytime curve and began from the start of the lift to peak velocity for the first pull and from the post-countermovement transition from negative to positive velocity to peak velocity for the second pull and jerk phases [19-21]. Power was calculated as the product of ground reaction force and bar/log velocity. Impulse $\left(\left(\mathrm{V}^{\mathrm{f}}-\mathrm{V}^{\mathrm{i}}\right) \mathrm{x}\right.$ mass $\left.(\mathrm{kg})\right)$ was obtained by subtracting initial bar/log velocity (i.e. starting velocity of each propulsive phase) from final bar/log velocity (i.e. maximum velocity reached during each propulsive phase), multiplied by the system mass (i.e. body mass plus 70\%1RM load). Force was presented as peak and mean values. Forces in the $\mathrm{X}$ and $\mathrm{Y}$ axis were calculated as medial (positive) and lateral (negative), and anterior (positive) and posterior (negative). Sum of mean forces in the $\mathrm{X}$ and $\mathrm{Y}$ axes were calculated as the total mean (e.g. $\mathrm{X}=$ medial + lateral forces). A definition for all the kinematic and temporal variables (adapted from Keogh et al. [22]) is given below. 
Peak vertical velocity $\left(\mathrm{m} . \mathrm{s}^{-1}\right)$ : The highest vertical velocity value of the bar/log during each phase of the lift.

Trunk angle $\left(^{\circ}\right)$ : The internal angle subtended from shoulder and hip to the horizontal axis, with larger values indicating a more vertical trunk position.

Hip angle $\left(^{\circ}\right)$ : The internal angle subtended from the shoulder, hip and and knee markers, with increasing values indicating greater hip extension.

Knee angle $\left({ }^{\circ}\right)$ : The internal angle subtended from the hip, knee and ankle markers, with $180^{\circ}$ indicating full knee extension.

Ankle angle $\left({ }^{\circ}\right)$ : The internal angle subtended from the knee, ankle and toe, with increasing values indicating plantarflexion.

\section{STATISTICAL ANALYSIS}

Means and standard deviations were used as measures of centrality and spread of data. Twotailed paired t-tests were used to determine if any statistical differences existed between the biomechanical variables measured between the log lift and clean and jerk from lift off to lift completion. Statistical significance was set at $\mathrm{p} \leq 0.05$. All analyses were performed using IBM Statistical Package for the Social Sciences (Version 20.0, SPSS for Windows).

Insert Figure 2 about here

\section{RESULTS}

Descriptive characteristics of all strongman athletes are presented in Table 1. On average strongman athletes trained four times a week for ninety minutes per session which totalled $6.4 \mathrm{hrs}$ of strongman/resistance training per week.

Insert Table 1 about here 
CLEAN AND JERK AND LOG LIFT KINETICS

Relatively few significant kinetic differences were found between the clean and jerk and log lift (see Table 2). The clean and jerk demonstrated significantly greater (35\%) mean posterior forces.

Insert Table 2 about here

Pictorial representations of group mean ground reaction force curves (normalised to percentage of mean lift time) for the clean and jerk and log lift are presented in Figure 3. The clean and jerk and log lift are very similar for all the lifting phases.

Insert Figure 3 about here

\section{CLEAN AND JERK AND LOG LIFT KINEMATICS}

The kinematic data can be observed in Table 3. The differences in stance width between the clean and jerk and log lift at lift off $(40.3 \pm 5.1 \mathrm{~cm}$ versus $40.7 \pm 4.3 \mathrm{~cm})$, top retrieve $(42.4 \pm$ $11.3 \mathrm{~cm}$ versus $40.2 \pm 6.4 \mathrm{~cm})$ and lift completion $(35.9 \pm 6.3 \mathrm{~cm}$ versus $37.9 \pm 5.8 \mathrm{~cm})$ (respectively) were found to be non-significant ( $\mathrm{p}>0.05$ ). However, significant kinematic differences were apparent between the clean and jerk and log lift throughout the lifting phases except for lift completion. Trunk angles were significantly different throughout the lifting phases between the lifts with, greater trunk (24\%) and hip ROM (9\%) associated with the log lift as compared to the clean and jerk. At 'top retrieve' the log lift was found to have significantly greater trunk ( $\uparrow 17 \%)$, hip $(\uparrow 15 \%)$ and knee $(\uparrow 12 \%)$ extension than the clean and jerk.

Insert Table 3 about here 


\section{CLEAN AND JERK AND LOG LIFT MECHANICAL DEMANDS}

Significant differences existed in peak and mean bar velocity between the clean and jerk and $\log$ lift, with the clean and jerk demonstrating greater peak velocities for the second pull $(\uparrow 17 \%)$ and jerk/push press $(\uparrow 14 \%)$ and greater mean velocities for the first pull ( $\uparrow 25 \%)$ and second pull ( $\uparrow 60 \%$ ) (see Table 4). The clean and jerk was found to have significantly higher ( $\mathrm{p}<0.05)$ peak and mean powers $(\uparrow 40 \%$ to $\uparrow 64 \%)$ in all lifting phases (i.e. first pull, second pull and jerk/push press). Significant differences in impulse were found between the lifting phases of the log lift and clean and jerk, with the log lift demonstrating greater impulse $(\uparrow 78 \%)$ in the second pull and the clean and jerk demonstrating greater impulse in the jerk/push press ( $\uparrow 13 \%)$. Lifting time was shorter in the clean and jerk $(\downarrow 22 \%)$ than the log lift however the differences were not statistically significant.

Insert Table 4 about here

\section{CLEAN AND JERK AND LOG LIFT BAR PATH KINEMATICS}

Group mean vertical and horizontal displacements of the bar/log paths for the clean and jerk and $\log$ lift normalised to $100 \%$ of lift time are presented in Figure 4. Greater horizontal displacements (from the bars' original vertical reference line) are evident in the second pull stage of the clean and jerk and in the log lifts jerk phase. Bar and log path trajectories, presented in Figure 5, demonstrate a more vertical trajectory in the log lift to top retrieve.

Insert Figures 4 and 5 about here

Three different log lifting techniques (Log lift with jerk; log lift with push press; and log lift and jerk without squat before second pull) were utilised by strongman athletes in this study. 
Vertical and horizontal displacements for the three techniques of log lift (normalised to $100 \%$ of lift time) are presented in Figure 6 and bar/log trajectories are presented in Figure 7. The squat pattern is clearly evident in the athlete's vertical displacement graphs (i.e. athletes 1 and 2). Similarities are evident with the clean and jerk bar trajectories however variations exist in $\log$ trajectories among the three log lifting techniques.

Insert Figures 6 and 7 about here

\section{DISCUSSION}

This is the first study to investigate the biomechanical characteristics of the strongman event 'the log lift'. Since the log lift is now being used by coaches in strength and conditioning practice as a means of performance enhancement [9], it is important to obtain data on the log lift that can provide insight into its effectiveness as a conditioning stimulus. This study sought to understand the acute stresses that the log lift imposed on the system and the likely chronic adaptations to this form of training. To achieve this, the kinetic and kinematic characteristics of the log lift were quantified and compared with the clean and jerk. We hypothesised that the log lift would show similar kinetic characteristics to the clean and jerk but many kinematic differences would exist between the lifts due to the varying diameters of the bar and $\log$.

The results of the present study supported the initial hypotheses, whereby the log lift was found to have very similar ground reaction forces in all three axes to the clean and jerk. The only significant difference between the lifts was the greater mean posterior force in the clean and jerk $(-91 \pm 27 \mathrm{~N}$ versus $-67 \pm 14 \mathrm{~N})$. The similarities in peak and mean vertical and propulsive forces in the present study between the log lift and the clean and jerk demonstrate that the log lift may be an efficient exercise stimulus for improving force production which is 
advantageous in terms of improving athletic performance. Weightlifting exercises such as the clean and jerk are commonly incorporated into power athletes' training programmes as the biomechanics of these exercises allow athletes to generate high forces at high velocities thus increasing power capability [7]. Researchers have demonstrated kinematic similarities between the propulsive phases in both weightlifting and jumping movements $[5,6,23]$ and significant relationships exist between weightlifting ability and power output during jumping $(r=0.59$ to 0.93$)$ and sprinting $(r=-0.52$ to -0.76$)$ [23-26] and tests of agility $(r=-0.41)$ [26]. Winwood and colleagues [27] found a clear large correlation between 1RM power clean and $\log$ clean and press $(r=0.67)$ repetitions (performed in a 60 second period) in twenty-three male semi-professional rugby players. Despite the different strength qualities measured i.e. maximal strength versus muscular and anaerobic endurance, the large correlation would appear to reflect the similarities in these exercises (i.e. main agonists, specific joint angles and direction of force application, muscle sequence patterns, specific postures, and velocities of movement).

The $\log$ lift is very similar to the clean and jerk phases reported in literature $[15,28]$ except in the preparation phase for the second pull. In the clean and jerk, as the barbell passes the knees, the knees shift forward and the barbell and hips move toward each other [29]. This motion initiates a stretch shortening cycle (known as the double knee bend) and repositions the lifter-barbell system so that the lifter is in a position where they can impart a large force to the barbell rapidly, resulting in a high power output [29-31]. In contrast, to prepare for the second pull in the log lift, athletes often place the log on the thighs and then prepare for the second pull by squatting down. This parallel-deep squat position may provide the lifter with three possible advantages during the second pull. It allows the lifter to bring the log close into their upper body which reduces the lumbar resistance moment arm and minimises the distance the log has to travel up the body from the initial start of the second pull to the top 
retrieve as well as increasing the ability to maximise vertical impulse by increasing the time to produce force. The fact that athletes can roll the log up the body during the second pull may make the log lift less technically demanding than the clean and jerk. However, rolling the log up the body from a 'resting position' may be more mechanically demanding than the clean and jerk. Such a contention seems supported to a certain extent, with significantly greater impulse $(293.3 \pm 115.5 \mathrm{~kg}-\mathrm{m} / \mathrm{s}$ versus $164.7 \pm 88.0 \mathrm{~kg}-\mathrm{m} / \mathrm{s})$ being observed in the $\log$ lift's second pull.

While it could be argued that the log lift technique may not elicit the same strength and power adaptations that are associated with the clean and jerk/push-press (because it does not incorporate the 'double knee bend'), this may be countered to some extent by the countermovement-based dip and drive phase of the jerk/press. Lake and colleagues [20] demonstrated that the demand of the push press (i.e. push press training with the load that maximised peak and mean power) is comparable with the jump squat and could provide a time-efficient combination of lower-body power and upper-body strength training. Results of the present study support this with the highest impulses' being observed in the jerk/pushpress phases in both the clean and jerk and log lift $(354.6 \pm 66.8 \mathrm{~kg}-\mathrm{m} / \mathrm{s}$ and $306.9 \pm 56.8 \mathrm{~kg}$ $\mathrm{m} / \mathrm{s}$; respectively). Interestingly, no significant differences existed between the clean and jerk and log lift for jerk/press push dip depth. Dip depth is important as greater ground reaction forces are possible in the 'thrust phase' with a shallower squat [32].

In the present study the clean and jerk was found to have significantly greater mean (1758 W to $3831 \mathrm{~W}$ versus $1194 \mathrm{~W}$ to $2340 \mathrm{~W}$ ) and peak ( $3527 \mathrm{~W}$ to $6629 \mathrm{~W}$ versus $2528 \mathrm{~W}$ to 4314 W) power in the lifting phases (i.e. first pull, second pull and jerk/press) compared to the log lift. Researchers have reported that the clean and jerk produces very high power outputs [25, 33], and prolonged weightlifting training can positively influence the neuroendocrine system 
to promote a biochemical environment more conducive to enhancing performance [34-36]. In a recent training study [37] that compared strongman training versus traditional training methods (which incorporated the log lift and the clean and jerk, respectively), on muscular function and performance, performance improvements of $0.2 \%$ to $7 \%$ were observed among thirty resistance trained rugby athletes. Interestingly, the study found no significant betweengroup differences in body composition and functional performance measures $(30 \mathrm{~m}$ sprint, 505 test, grip strength, $15 \mathrm{~m} 70 \mathrm{~kg}$ sled push, and horizontal and vertical jump tests) after seven weeks of resistance training.

Peak bar velocity was significantly higher in the clean and jerk in the second pull $(2.18 \pm$ $0.17 \mathrm{~ms}^{-1}$ versus $\left.1.87 \pm 0.26 \mathrm{~ms}^{-1}\right)$ and the jerk/push-press $\left(1.82 \pm 0.09 \mathrm{~ms}^{-1}\right.$ versus $1.60 \pm$ $\left.0.10 \mathrm{~ms}^{-1}\right)$. Waller and colleagues [2] suggested that implement diameter changes the mechanics of the log press because the log cannot be kept as close to the body as that of a traditional barbell, which may hinder the athletes ability to impart vertical force onto the log. Other factors such as jerking/pressing in a neutral grip with the neck retracted and the head tilted back to minimise horizontal displacement (and lumbar hyperextension) during the jerk/press could also have an impact on log jerk/press velocity. Furthermore, the log lacks the deformation characteristics (attributed to the mechanical properties and physical dimensions) associated with Olympic weightlifting bars, which offer appropriate "spring" for use in weightlifting and competition [38].

Understanding bar path kinematics is important as researchers have demonstrated that improvements in bar path kinematics lead to improved bar kinetics (i.e. peak force and peak power) [39]. The present study sought to examine the horizontal and vertical displacement characteristics associated with the bar/log paths to determine if differences existed in bar path kinematics. The clean and jerk and log lift were found to have similar bar path kinematics; 
however a drop in vertical displacement before the second pull in the log lift was clearly evident in the athletes who utilised the squat technique. A range of horizontal displacements were also observed among strongman athletes in both the clean and jerk and log lift. Garhammer and colleagues [40] suggested that a number of factors can influence the optimum trajectory for an athlete including relative body segment lengths and whether the athlete jumps forward or backward to catch the bar. The results of the present study and that of Garhammer et al. [40] demonstrate that lifting trajectories are unique to each individual.

Our group mean results were similar to previous findings reported in literature [39, 40] in which the movements of the bar and log were generally toward the lifter (positive direction) in the first pull, followed by movement away from the lifter during the second pull (negative direction), and then again toward the lifter (after the point of maximum hip extension associated with the second pull). Interestingly, greater mean horizontal displacements were associated with the clean and jerk in the second pull while greater horizontal displacements were seen in the log press/jerk. Such data supports our initial hypothesis in which we surmised that the diameter of the log would change lifting kinematics because the log cannot be kept as close to the body as that of a traditional barbell. The greater horizontal displacements associated with the log lift jerk/press, supports the views of Waller and colleagues [2] in regard to implement diameters and pressing mechanics. It could also be argued that the greater horizontal movement associated with the log jerk/press could require greater core stabilisation and overall body balance, however studies are needed to validate such views. Future research could investigate the effect of different log sizes on muscle activity and bar path kinematics.

This study also sought to provide further insight into the kinematics of the log lift by comparing stance widths and joint angles with the clean and jerk during key components of 
the lifts. Interestingly, no significant differences in stance width were found at lift off, top retrieve and lift completion, however significant differences in joint and segmental angles were found throughout the lifting phases, except at lift completion. Significant differences were apparent at lift off with the log lift having greater trunk $\left(7.0 \pm 8.0^{\circ}\right.$ versus $\left.20.5 \pm 10.1^{\circ}\right)$ and hip $\left(51.8 \pm 6.4^{\circ}\right.$ versus $\left.60.0 \pm 5.9^{\circ}\right)$ flexion angles than the clean and jerk. The differences in trunk and hip angles at lift off are likely to be attributed to the center of the log being further away from the lifter at the start of the lift to that of the barbell used in the clean and jerk. Greater trunk extension was seen in the log lift at the top of the first pull in which the athletes had to pull the log up higher to clear the knees as opposed to the barbell with the clean and jerk. Greater dorsiflexion $\left(84.5 \pm 6.1^{\circ}\right.$ versus $\left.96.2 \pm 3.0^{\circ}\right)$ and greater knee flexion $(99.2 \pm 24.8$ versus $139.7 \pm 11.1)$ angles were seen in the $\log$ lift at start of the second pull which reflected the deep squat position associated with this phase.

Significantly greater trunk extension was also observed in the log lift during the middle of the second pull $\left(113.3 \pm 13.7^{\circ}\right.$ versus $\left.94.0 \pm 9.8^{\circ}\right)$, top retrieve $\left(105.8 \pm 2.4^{\circ}\right.$ versus $\left.90.7 \pm 6.0^{\circ}\right)$ and bottom of the dip and drive $\left(92.8 \pm 5.3^{\circ}\right.$ versus $\left.86.5 \pm 2.1^{\circ}\right)$. In order for athletes to move the $\log$ in a vertical direction up the body, greater trunk extension was required to minimise forward horizontal displacement of the log. The large variances associated with the knee $\left( \pm 24^{\circ}\right)$, hip $\left( \pm 28^{\circ}\right)$ and trunk angles $\left( \pm 13^{\circ}\right)$ in the log lift at the start of the second pull demonstrate that strongman athletes utilise various lifting strategies for the second pull with a $70 \%$ 1RM clean and jerk load. Interestingly, trunk and hip range of motion was significantly greater $\left(24^{\circ}\right.$ and $9^{\circ}$ respectively) in the log lift compared to the clean and jerk. Coaches who are trying to develop forceful hip extension in their athletes could find the log lift to be an effective training exercise to achieve this. Future research may wish to investigate the kinematics and kinetics of log lifting with a range of different size logs and loads. Such research would give insight into the force-velocity characteristics of log lifting and the 
kinematic variances associated with performing log lifts with logs of various diameters and loads.

\section{CONCLUSION}

The results of this study provide coaches with the first biomechanical description of the $\log$ lift's kinetic and kinematic characteristics and how these compare to the clean and jerk. The $\log$ lift and clean and jerk force and power profiles show that these exercises are effective conditioning exercises that enables the generation of high vertical forces and power outputs. The log lift may be an effective lifting alternative for coaches who have athletes that; a) are not overly proficient in the clean and jerk; b) for athletes that need to develop forceful hip extension, especially to overcome loads positioned more anterior to their centre of mass than that commonly seen in the clean and jerk; and c) for athletes who may prefer to press with a neutral grip. Coaches who wish to utilise the log lift in conditioning practice should be aware that load, log type and size may all influence log lift biomechanical characteristics. Coaches should consider individualised exercise prescription with a sports specific approach to elicit optimal neuromuscular adaptations. Future biomechanical studies are needed to investigate the effect of load and log size on lifting kinematics and kinetics.

\section{ACKNOWLEDGEMENTS}

The authors would like to thank each of the strongman athletes who participated in this study and Anna Lorimer for her help with data collection. 


\section{REFERENCES}

1. Winwood, P.W., Keogh, J.W.L. and Harris, N.K., The Strength and Conditioning Practices of Strongman Competitors, Journal of Strength \& Conditioning Research, 2011, 25(11), 3118-28.

2. Waller M, Piper T, and Townsend R., Strongman Events and Strength and Conditioning Programs, Strength and Conditioning Journal, 2003, 25(5), 44-52.

3. Durall, C.J., Manske, R.C. and Davies, G.J., Avoiding Shoulder Injury from Resistance Training, Strength and Conditioning Journal, 2001, 23(5), 10-8.

4. Ellenbecker, T.S., Modification of Traditional Exercises for Shoulder Rehabilitation and a Return-to-Lifting Program, New York, USA, Thieme Medical Publishers, Inc, 2006.

5. Canavan, P.K., Garrett, G.E., Armstrong, L.E., Kinematic and Kinetic Relationships Between an Olympic-Style Lift and the Vertical Jump, Journal of Strength \& Conditioning Research, 1996, 10(2), 127-30.

6. Garhammer, J. and Gregor, R., Propulsion Force as a Function of Intensity for Weightlifting and Vertical Jumping, Journal of Applied Sport Science Research, 1992, 6, 129-34.

7. Hori, N., Newton, R.U., Nosaka, K. and Stone, M.H., Weightlifting Exercises Enhance Athletic Performance that Requires High-Load Speed Strength, Strength and Conditioning Journal, 2005, 27, 50-5.

8. Hedrick, A. and Wada, H., Weightlifting Movements: Do the Benefits Outweigh the Risks? Strength and Conditioning Journal, 2008, 30(6), 26-34.

9. Winwood, P.W., Cronin, J.B., Dudson, M.K., Gill, N.D. and Keogh, J.W.L., How Coaches Use Strongman Implements in Strength and Conditioning Practice, International Journal of Sports Science \& Coaching, In Press.

10. Winwood, P.W., Hume, P.A., Cronin, J.B. and Keogh, J.W.L., Retrospective Injury Epidemiology of Strongman Athletes, Journal of Strength \& Conditioning Research, 2014, 28(1), 28-42.

11. Winwood, P.W., Cronin, J.B., Brown, S.R. and Keogh, J.W.L., A Biomechanical Analysis of the Farmers Walk and Comparison with the Deadlift and Unloaded Walk, International Journal of Sports Science and Coaching, In Press.

12. Winwood, P.W., Cronin, J.B., Brown, S.R. and Keogh, J.W.L. A Biomechanical Analysis of the Heavy Sprint-Style Sled Pull and Comparison with the Back Squat, International Journal of Sports Science \& Coaching, In Press.

13. Wilson, G., Strength and Power Assessment, Applied Anatomy and Biomechanics in Sport, Melbourne, Blackwell Scientific Publications, 1994.

14. Stone, M.H., Pierce, K.C., Sands, W.A. and Stone, M.E. Weightlifting: Program Design, Strength and Conditioning Journal, 2006, 28(2), 10-7.

15. Stone, M.H., Pierce, K.C., Sands, W.A. and Stone, M.E. Weightlifting: A Brief Overview, Strength and Conditioning Journal, 2006, 28(1), 50-66.

16. Winter, D.A. Biomechanics and Motor Control of Human Movement, 4 ed, Hoboken, New Jersey, John Wiley \& Sons, 2009.

17. Garhammer, J. and Takano, B. Training for Weightlifting, In: Komi P, editor. Strength and Power in Sport, 2 ed, Bodmin, Cornwall, Blackwell Science, 2003.

18. Bowerman, E., Whatman, C., Harris, N. and Bradshaw, E., Reliability of 2D Lower Extremity Alignment Measures in Elite Adolescent Ballet Dancers, New Zealand Journal of Sports Medicine, 2013, 40(2), 70-3.

19. Garhammer, J. A Comparison of Maximal Power Outputs Between Elite Male and Female Weightlifters in Competition, International Journal of Sports Biomechanics, 1991, 7(7-11). 
20. Lake, J.P., Mundy, P.D. and Comfort, P. Power and Impulse Applied During Push Press Exercise, Journal of Strength \& Conditioning Research, 2014, 28(9), 2552-2559.

21. Lake, J., Lauder, M., Smith, N. and Shorter, K. A Comparison of Ballistic and Nonballistic Lower-Body Resistance Exercise and the Methods Used to Identify Their Positive Lifting Phases, Journal of Applied Biomechanics, 2012, 28, 431-437.

22. Keogh, J., Kattan, A., Logan, S., Bensley, J., Muller, C. and Powell, L., A Preliminary Kinematic Gait Analysis of a Strongman Event: The Farmers Walk, Sports, 2014, 2, 24-33. 23. Carlock, J.M., Smith, S.L., Hartman, M.J., Morris, R.T., Ciroslan, D.A., Pierce, K.C., et al, The Relationship Between Vertical Jump Power Estimates and Weightlifting Ability: A Field-Test Approach, Journal of Strength \& Conditioning Research, 2004, 18(3), 534-9.

24. Baker, D. and Nance, S., The Relation Between Running Speed and Measures of Strength and Power in Professional Rugby League Players, Journal of Strength \& Conditioning Research, 1999, 13(3), 230-5.

25. Tricoli, V., Lamas, L., Carnevale, R. and Ugrinowitsch, C., Short-Term Effects on Lower-Body Functional Power Development: Weightlifting vs. Vertical Jump Training Programmes, Journal of Strength \& Conditioning Research, 2005, 19(2), 433-7.

26. Hori, N., Newton, R.U., Andrews, W.A., Kawamori, N., McGuigan, M.R. and Nosaka K., Does Performance of Hang Power Clean Differentiate Performance of Jumping, Sprinting, and Changing of Direction? Journal of Strength \& Conditioning Research, 2008, 22(2), 412-8.

27. Winwood, P.W., Keogh, J.W.L., Harris, N.K. and Weaver, L.M., Interrelationships Between Strength, Anthropometrics and Strongman Performance in Novice Strongman Athletes, Journal of Strength \& Conditioning Research, 2012, 26(2), 513-22.

28. Storey, A. and Smith, H.K., Unique Aspects of Competitive Weightlifting. Sports Medicine, 2012, 42(9), 769-90.

29. Baumann, W., Gross, V., Quade, K., Galbierz, P. and Schwirtz, A., The Snatch Technique of World Class Weightlifters at the 1985 World Championships, International Journal of Sports Biomechanics, 1988, 4(1), 68-89.

30. Enoka, R.M., The Pull in Olympic Weightlifting, Medicine and Science in Sports, $1979,11,131-7$.

31. Garhammer, J., Power Production by Olympic Weightlifters, Medicine \& Science in Sports \& Exercise, 1980, 12(1), 54-60.

32. Kauhanen, K., Hakkinen, K. and Komi, P.V. A Biomechanical Analysis of the Snatch and Clean \& Jerk Techniques of Finnish Elite and District Level Weightlifters, Scandinavian Journal of Sport Sciences, 1984, 6, 47-56.

33. McBride, J.M., Triplett-McBride, T., Davie, A. and Newton, R.U. A Comparison of Strength and Power Characteristics Between Power lifters, Olympic lifters and Sprinters, Journal of Strength \& Conditioning Research, 1999, 13(1), 58-66.

34. $\quad$ Fry, A.C., Kraemer, W.J., Stone, E.M., Warren, B.J., Fleck, S.J., Kearney, J.T., et al. Endocrine Responses to Overreaching Before and After 1 Year of Weightlifting, Canadian Journal of Applied Physiology, 1994, 19, 400-410.

35. Hakkinen, K., Pakarinen, A., Alen, M., Kauhanen, H. and Komi V, P. Neuromuscular and Hormonal Adaptations in Athletes to Strength Training in Two Years, Journal of Applied Physiology, 1988, 65(6), 2406-2412.

36. Kraemer, W.J., Fry, A.C., Warren, B.J., Stone, M.H., Fleck, S.J., Kearney, J.T., et al. Acute Hormonal Responses in Elite Junior Weightlifters, International Journal of Sports Medicine, 1992, 13(20), 103-109.

37. Winwood, P.W., Cronin, J.B., Posthumus, L.R., Finlayson, S.J., Gill, N.D. and Keogh J.W.L. Strongman Versus Traditional Resistance Training Effects on Muscular Function and Performance, Journal of Strength \& Conditioning Research, 2015, 29(2), 429-39.

38. Chiu, L.Z.F., Mechanical Properties of Weightlifting Bars, Journal of Strength \& Conditioning Research, 2010, 24(9), 2390-9 
39. Winchester, J.B., Erickson, T.M., Blaak, J.B. and McBride, J.M., Changes in Bar-Path Kinematics and Kinetics After Power Clean Training, Journal of Strength \& Conditioning Research, 2005, 19(1), 177-83.

40. Garhammer, J., Biomechanical Profiles of Olympic Weightlifters, International Journal of Sports Biomechanics, 1985, 1, 122-30.

\section{Legend of Figures}

Figure 1: Sony Camera and Force Platform Set Up .28

Figure 2: Pictorial Representation of the Four Angles Measured at; A) Lift Off (LO); B) Top of First Pull (TFP); C) Start of Second Pull (SSP); D) Middle of the Second Pull (At Maximum Point of Planterflexion) (MSP); E) Top Retrieve (Point at which Log Touches Top of Chest) (TR); F) Bottom of Dip and Drive (BDD) and; G) at Lift Completion (LC) in the Log Lift.

Figure 3: Group Mean Vertical (top), Anterior/Posterior (middle) and Medial/Lateral (bottom) Force-Time Curves (Normalised to Percentage of Mean Lift Time) Obtained with a 70\% 1-Repetition Maximum Load for the Clean and Jerk and Log lift. 30 Figure 4: Vertical (left) and Horizontal (right) Displacements of the Bar Paths for the Clean and Jerk and Log Lift Normalised to $100 \%$ of Mean Lift Time. Circles Indicate (from Bottom to Top) Top of First Pull, Middle of the Second Pull (At Maximum Point of Planterflexion), Top Retrieve and Bottom of the Dip and Drive.

Figure 5: Group Mean Bar/Log Path Trajectories for the Clean and Jerk and Log Lift. Circles Indicate (from Bottom to Top) Top of First Pull, Middle of the Second Pull (At Maximum Point of Planterflexion), Top Retrieve and Bottom of the Dip and Drive.

Figure 6: Pictorial representations of three log lifting techniques performed by strongman athletes. Vertical (left) and Horizontal (right) Displacements of the Bar Paths Normalised to $100 \%$ of Mean Lift Time. Athlete 1: Log Lift with Jerk; Athlete 2: Log Lift with Push Press; Athlete 3: Log Lift and Jerk without Squat before Second Pull.

Figure 7: Pictorial Representations of Bar/Log Trajectories of the Three Log Lifting

Techniques Performed by Strongman Athletes. Athlete 1: Log Lift with Jerk; Athlete 2: Log Lift with Push Press; Athlete 3: Log Lift and Jerk without Squat before Second Pull............34

\section{Legend of Tables}

Table 1: Demographics, Training Characteristics and Strength Measures (mean $\pm S D$ ) for

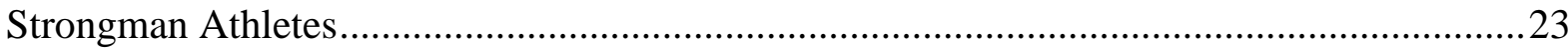

Table 2: External Ground Reaction Forces of the Clean and Jerk and Log lift .....................24 Table 3: Kinematics of Trunk, Hip, Knee and Ankle Angles Performed from the Lift Off to Lift Completion for the Clean and Jerk and Log Lift .25 Table.4: A Comparison of the Mechanical Demand Characteristics of the Clean and Jerk and Log Lift 
Table 1: Demographics, Training Characteristics and Strength Measures (mean $\pm S D$ ) for Strongman Athletes

\begin{tabular}{|c|c|}
\hline & $\begin{array}{l}\text { All Strongman athletes } \\
(\mathrm{n}=6)\end{array}$ \\
\hline \multicolumn{2}{|l|}{ Demographics } \\
\hline $\operatorname{Age}(y)$ & $24.0 \pm 3.9$ \\
\hline Height (cm) & $181.6 \pm 9.4$ \\
\hline Body mass (kg) & $112.9 \pm 28.9$ \\
\hline \multicolumn{2}{|l|}{ Training } \\
\hline Resistance training experience (y) & $6.5 \pm 2.7$ \\
\hline Strongman implement training experience (y) & $2.7 \pm 1.6$ \\
\hline Number of resistance training sessions per week & $4.2 \pm 1.2$ \\
\hline Average time of resistance training session (min) & $90.8 \pm 30.4$ \\
\hline \multicolumn{2}{|l|}{ Strength $(1 R M)$} \\
\hline Clean and Jerk (kg) & $116.7 \pm 20.4$ \\
\hline Clean and Jerk (kg/kg.bm) & $1.05 \pm 0.12$ \\
\hline
\end{tabular}


Table 2: External Ground Reaction Forces of the Clean and Jerk and Log lift

\begin{tabular}{lll}
\hline & Clean and Jerk & Log Lift \\
\cline { 1 - 2 } Z axis & $4616 \pm 1486$ & $4552 \pm 1306$ \\
Peak vertical force (N) & $1921 \pm 385$ & $1940 \pm 424$ \\
\hline Mean vertical force (N) & & \\
\hline Peakis & $1433 \pm 1173$ & $1238 \pm 899$ \\
Mean anterior force (N) & $82 \pm 31$ & $76 \pm 36$ \\
Peak posterior force (N) & $-1431 \pm 1096$ & $-1257 \pm 1015$ \\
Mean posterior force (N) & $-91 \pm 27^{\dagger 0.034}$ & $-67 \pm 14$ \\
Mean of Y forces (N) & $2 \pm 3$ & $1 \pm 1$ \\
\hline X axis & $654 \pm 484$ & $592 \pm 403$ \\
\hline Peak medial force (N) & $48 \pm 32$ & $44 \pm 11$ \\
Mean medial force (N) & $-741 \pm 616$ & $-803 \pm 555$ \\
Peak lateral force (N) & $-43 \pm 17$ & $-43 \pm 10$ \\
Mean lateral force (N) & $2 \pm 3$ & $2 \pm 2$ \\
Mean of X forces (N) & & \\
\hline Data expressed as mean & &
\end{tabular}

Data expressed as mean \pm SD.

$\dagger$ significantly different to other level of variable 
Table 3: Kinematics of Trunk, Hip, Knee and Ankle Angles Performed from the Lift Off to Lift Completion for the Clean and Jerk and Log Lift

\begin{tabular}{|c|c|c|}
\hline & Clean and Jerk & Log Lift \\
\hline \multicolumn{3}{|l|}{ Lift off $(L O)$} \\
\hline Trunk angle $\left({ }^{\circ}\right)$ & $20.5 \pm 10.1^{\dagger 0.014}$ & $7.0 \pm 8.0$ \\
\hline Hip angle $\left({ }^{\circ}\right)$ & $60.0 \pm 5.9^{\dagger 0.0017}$ & $51.8 \pm 6.4$ \\
\hline Knee angle $\left({ }^{\circ}\right)$ & $103.5 \pm 15.5$ & $114.2 \pm 13.9$ \\
\hline Ankle angle $\left({ }^{\circ}\right)$ & $85.0 \pm 7.8$ & $92.8 \pm 8.8$ \\
\hline \multicolumn{3}{|c|}{ Top of first pull (TFP) } \\
\hline Trunk angle $\left({ }^{\circ}\right)$ & $36.7 \pm 5.9^{\dagger 0.046}$ & $51.7 \pm 14.6$ \\
\hline Hip angle $\left(^{\circ}\right)$ & $101.0 \pm 5.2$ & $112.8 \pm 16.7$ \\
\hline Knee angle $\left({ }^{\circ}\right)$ & $143.0 \pm 12.9$ & $135.5 \pm 15.2$ \\
\hline Ankle angle $\left({ }^{\circ}\right)$ & $99.8 \pm 4.9^{\dagger 0.028}$ & $94.2 \pm 4.6$ \\
\hline \multicolumn{3}{|c|}{ Start of second pull (SSP), } \\
\hline Trunk angle $\left({ }^{\circ}\right)$ & $45.0 \pm 8.0$ & $51.3 \pm 13.0$ \\
\hline Hip angle $\left({ }^{\circ}\right)$ & $108.5 \pm 4.9$ & $87.8 \pm 28.1$ \\
\hline Knee angle $\left({ }^{\circ}\right)$ & $139.7 \pm 11.1^{\dagger 0.019}$ & $99.2 \pm 24.8$ \\
\hline Ankle angle $\left({ }^{\circ}\right)$ & $96.2 \pm 3.0^{\dagger 0.013}$ & $84.5 \pm 6.1$ \\
\hline \multicolumn{3}{|c|}{ Middle of the second pull (MSP) } \\
\hline Trunk angle $\left({ }^{\circ}\right)$ & $94.0 \pm 9.8^{\dagger 0.048}$ & $111.3 \pm 13.7$ \\
\hline Hip angle $\left({ }^{\circ}\right)$ & $164.5 \pm 12.9$ & $184.3 \pm 19.9$ \\
\hline Knee angle $\left({ }^{\circ}\right)$ & $147.0 \pm 9.5$ & $144.8 \pm 7.2$ \\
\hline Ankle angle $\left(^{\circ}\right)$ & $122.0 \pm 7.5$ & $112.2 \pm 11.5$ \\
\hline \multicolumn{3}{|l|}{ Top retrieve $(T R)$} \\
\hline Trunk angle $\left({ }^{\circ}\right)$ & $90.7 \pm 6.0^{\dagger 0.002}$ & $105.8 \pm 2.4$ \\
\hline Hip angle $\left({ }^{\circ}\right)$ & $158.0 \pm 14.8^{\dagger 0.005}$ & $182.3 \pm 5.3$ \\
\hline Knee angle $\left({ }^{\circ}\right)$ & $124.5 \pm 13.4^{\dagger 0.033}$ & $138.8 \pm 11.1$ \\
\hline Ankle angle $\left({ }^{\circ}\right)$ & $82.8 \pm 4.6$ & $87.3 \pm 8.2$ \\
\hline \multicolumn{3}{|c|}{ Bottom of dip and drive (BDD) } \\
\hline Trunk angle $\left(^{\circ}\right)$ & $86.5 \pm 2.1^{\dagger 0.018}$ & $92.8 \pm 5.3$ \\
\hline Hip angle $\left({ }^{\circ}\right)$ & $142.5 \pm 6.2$ & $150.0 \pm 13.4$ \\
\hline Knee angle $\left({ }^{\circ}\right)$ & $106.3 \pm 10.8$ & $106.2 \pm 11.5$ \\
\hline Ankle angle $\left(^{\circ}\right)$ & $81.0 \pm 3.9$ & $79.3 \pm 2.6$ \\
\hline \multicolumn{3}{|c|}{ Lift Completion (LC) } \\
\hline Trunk angle $\left({ }^{\circ}\right)$ & $87.3 \pm 4.6$ & $89.7 \pm 3.6$ \\
\hline Hip angle $\left(^{\circ}\right)$ & $175.7 \pm 8.1$ & $177.3 \pm 8.4$ \\
\hline Knee angle $\left({ }^{\circ}\right)$ & $166.3 \pm 6.4$ & $166.8 \pm 6.1$ \\
\hline
\end{tabular}


Ankle angle $\left(^{\circ}\right)$

$$
100.0 \pm 3.9
$$

$101.8 \pm 6.8$

Range of Motion (ROM)

Trunk ROM ( $\left.{ }^{\circ}\right)$

$66.8 \pm 12.0^{\dagger 0.010}$

$82.7 \pm 8.4$

Hip ROM $\left(^{\circ}\right)$

$115.7 \pm 10.4^{\dagger 0.028}$

$125.5 \pm 8.9$

Knee ROM $\left(^{\circ}\right)$

$62.8 \pm 18.7$

$52.7 \pm 9.3$

Ankle ROM $\left(^{\circ}\right)$

$15.0 \pm 7.6$

$9.0 \pm 4.6$

Data expressed as mean $\pm \mathrm{SD}$

$\dagger$ significantly different to other level of variable 
Table.4: A Comparison of the Mechanical Demand Characteristics of the Clean and Jerk and Log Lift

Clean and Jerk $\quad$ Log Lift

\begin{tabular}{|c|c|c|}
\hline \multicolumn{3}{|l|}{ Peak Vertical Velocity $\left(\mathrm{m} \cdot \mathrm{s}^{-1}\right)$} \\
\hline First pull & $1.51 \pm 0.20$ & $1.35 \pm 0.21$ \\
\hline Second pull & $2.18 \pm 0.17^{\dagger 0.014}$ & $1.87 \pm 0.26$ \\
\hline Jerk/Push press & $1.82 \pm 0.09^{\dagger 0.002}$ & $1.60 \pm 0.10$ \\
\hline \multicolumn{3}{|l|}{ Mean Vertical Velocity $\left(\mathrm{m}^{-1}{ }^{-1}\right)$} \\
\hline First pull & $0.75 \pm 0.15^{\dagger 0.016}$ & $0.60 \pm 0.10$ \\
\hline Second pull & $1.69 \pm 0.15^{\dagger 0.011}$ & $1.06 \pm 0.41$ \\
\hline Jerk/Push press & $0.97 \pm 0.08$ & $0.88 \pm 0.07$ \\
\hline \multicolumn{3}{|l|}{ Peak Power (W) } \\
\hline First pull & $3527 \pm 1172^{\dagger 0.036}$ & $2528 \pm 679$ \\
\hline Second pull & $6629 \pm 2068^{\dagger 0.028}$ & $4314 \pm 1369$ \\
\hline Jerk/Push press & $5629 \pm 1565^{\dagger 0.009}$ & $3699 \pm 618$ \\
\hline \multicolumn{3}{|l|}{ Mean Power (W) } \\
\hline First pull & $1758 \pm 586^{\dagger 0.030}$ & $1194 \pm 323$ \\
\hline Second pull & $3831 \pm 1079^{\dagger 0.018}$ & $2340 \pm 1302$ \\
\hline Jerk/Push press & $2960 \pm 802^{\dagger 0.041}$ & $1922 \pm 591$ \\
\hline \multicolumn{3}{|l|}{ Impulse (kg-m/s) } \\
\hline First pull & $291.8 \pm 95.2$ & $253.6 \pm 65.0$ \\
\hline Second pull & $164.7 \pm 88.0^{\dagger 0.042}$ & $293.3 \pm 115.5$ \\
\hline Jerk/Push press & $345.6 \pm 66.8^{\dagger 0.003}$ & $306.9 \pm 56.8$ \\
\hline Jerk/Push press dip-depth (cm) & $18.0 \pm 6.6$ & $17.4 \pm 4.4$ \\
\hline Total Lift time (s) & $6.20 \pm 1.96$ & $7.96 \pm 3.77$ \\
\hline
\end{tabular}

Data expressed as mean \pm SD.

$\uparrow$ significantly different to other level of variable 


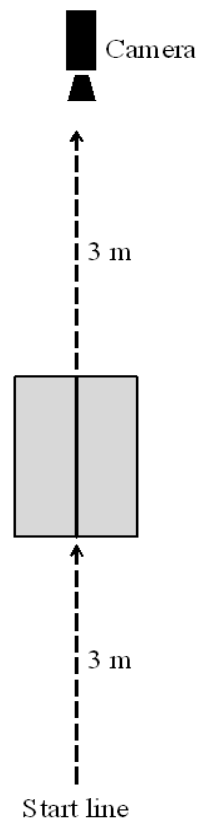

Camera

Figure 1: Sony Camera and Force Platform Set Up 


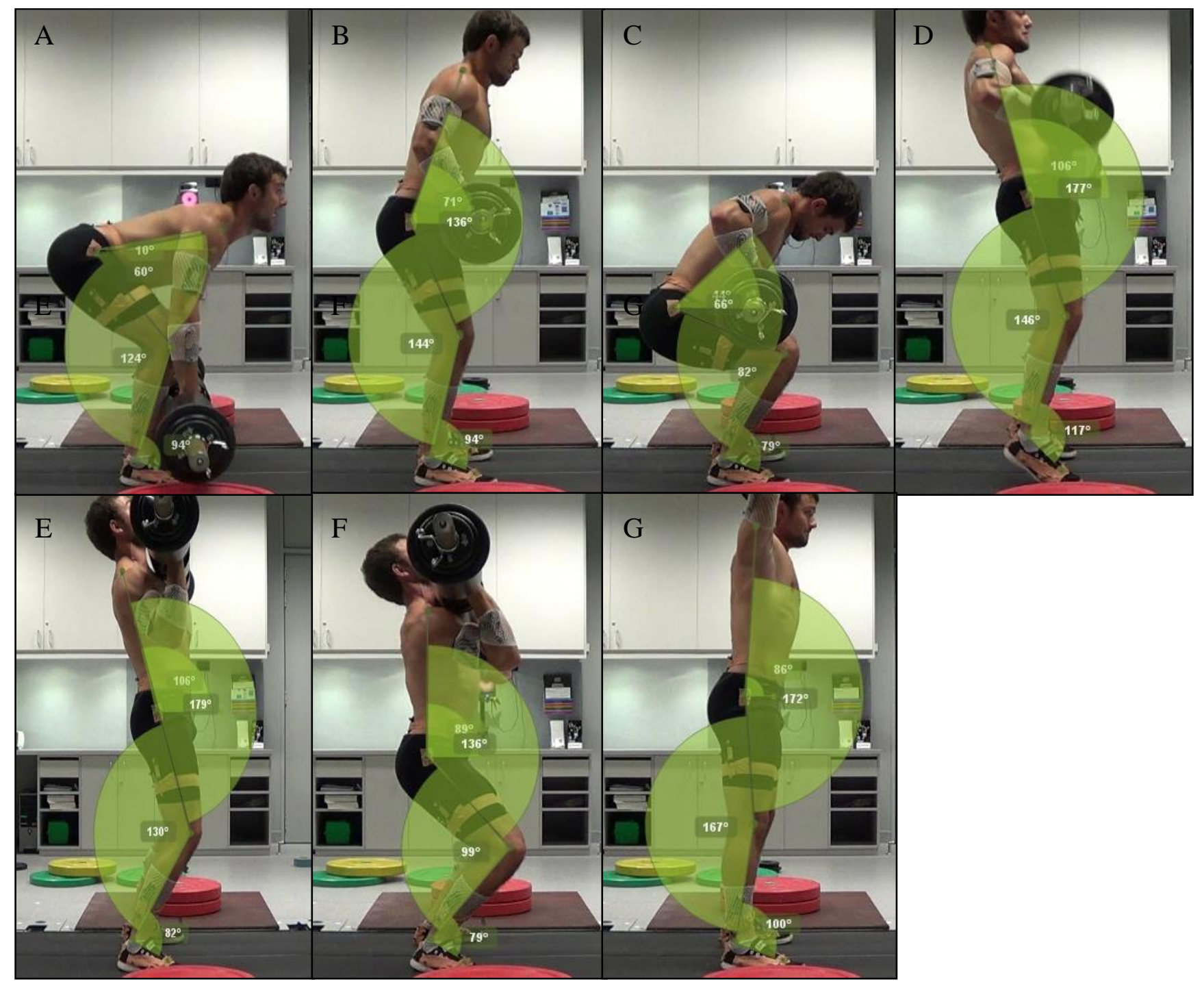

Figure 2: Pictorial Representation of the Four Angles Measured at; A) Lift Off (LO); B) Top of First Pull (TFP); C) Start of Second Pull (SSP); D) Middle of the Second Pull (At Maximum Point of Planterflexion) (MSP); E) Top Retrieve (Point at which Log Touches Top of Chest) (TR); F) Bottom of Dip and Drive (BDD) and; G) at Lift Completion (LC) in the Log Lift. 

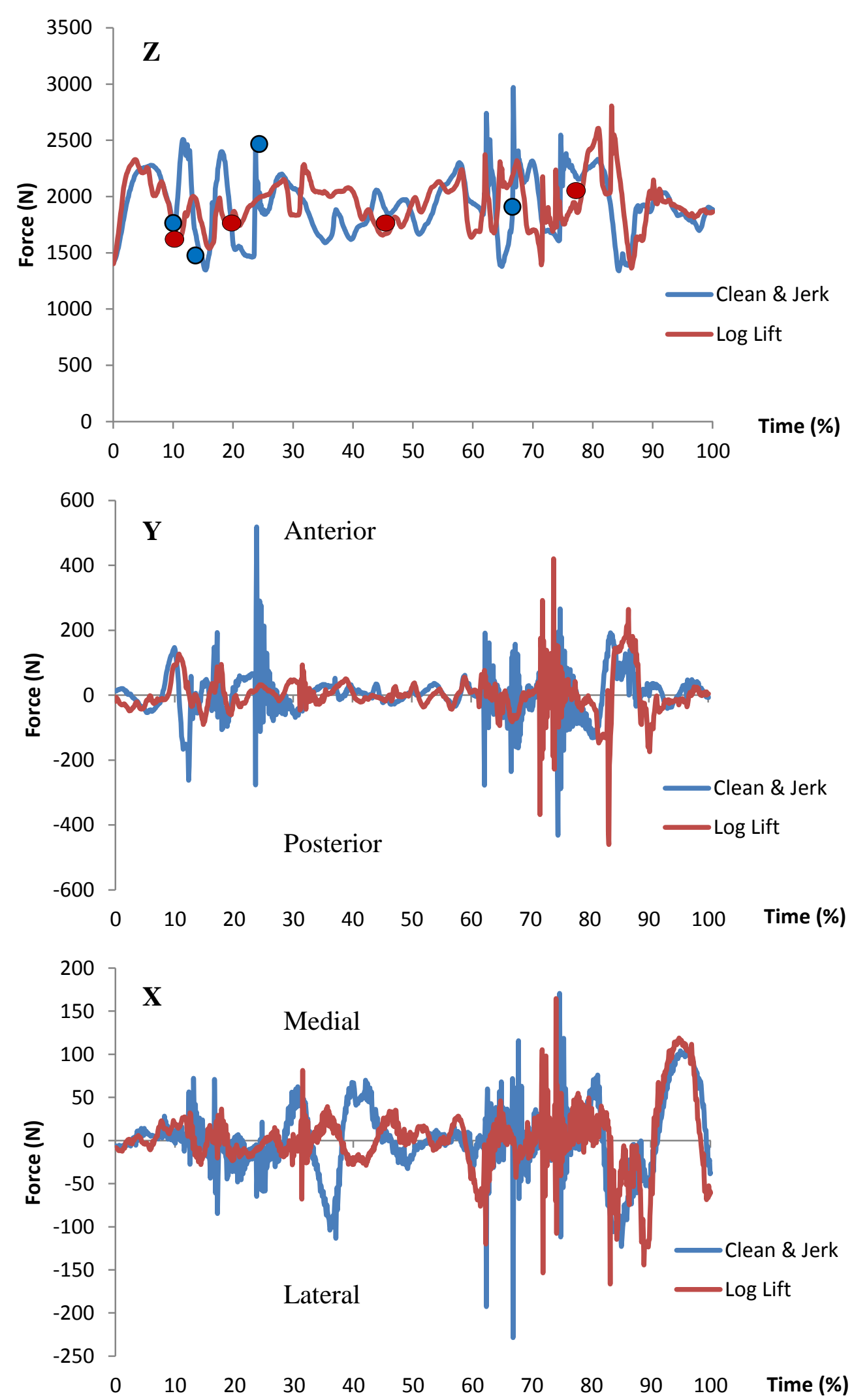

Figure 3: Group Mean Vertical (top), Anterior/Posterior (middle) and Medial/Lateral (bottom) Force-Time Curves (Normalised to Percentage of Mean Lift Time) Obtained with a 70\% 1-Repetition Maximum Load for the Clean and Jerk and Log lift. Circles Indicate (from Left to right) Top of First Pull, Middle of the Second Pull (At Maximum Point of Planterflexion), Top Retrieve and Bottom of the Dip and Drive. 

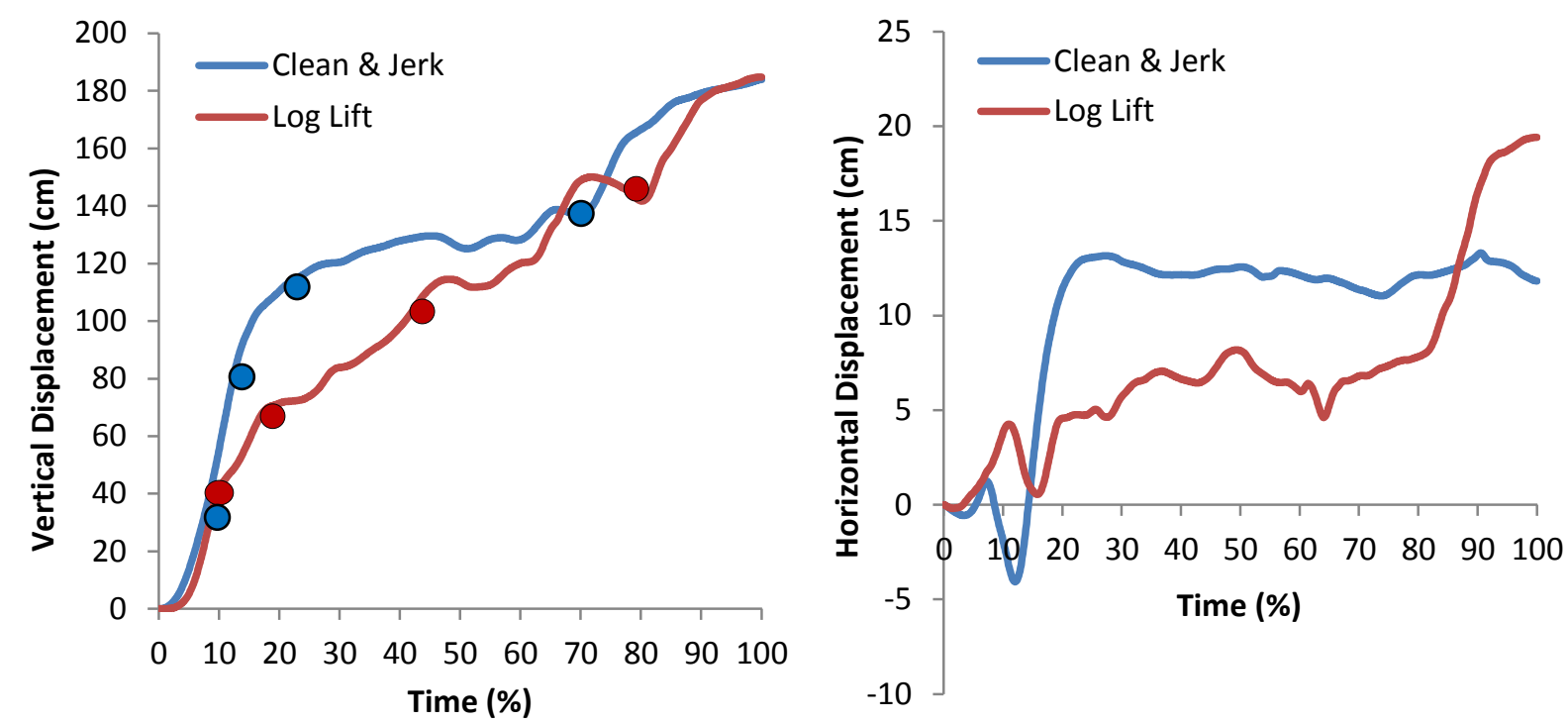

Figure 4: Vertical (left) and Horizontal (right) Displacements of the Bar Paths for the Clean and Jerk and Log Lift Normalised to $100 \%$ of Mean Lift Time. Circles Indicate (from Bottom to Top) Top of First Pull, Middle of the Second Pull (At Maximum Point of Planterflexion), Top Retrieve and Bottom of the Dip and Drive. 


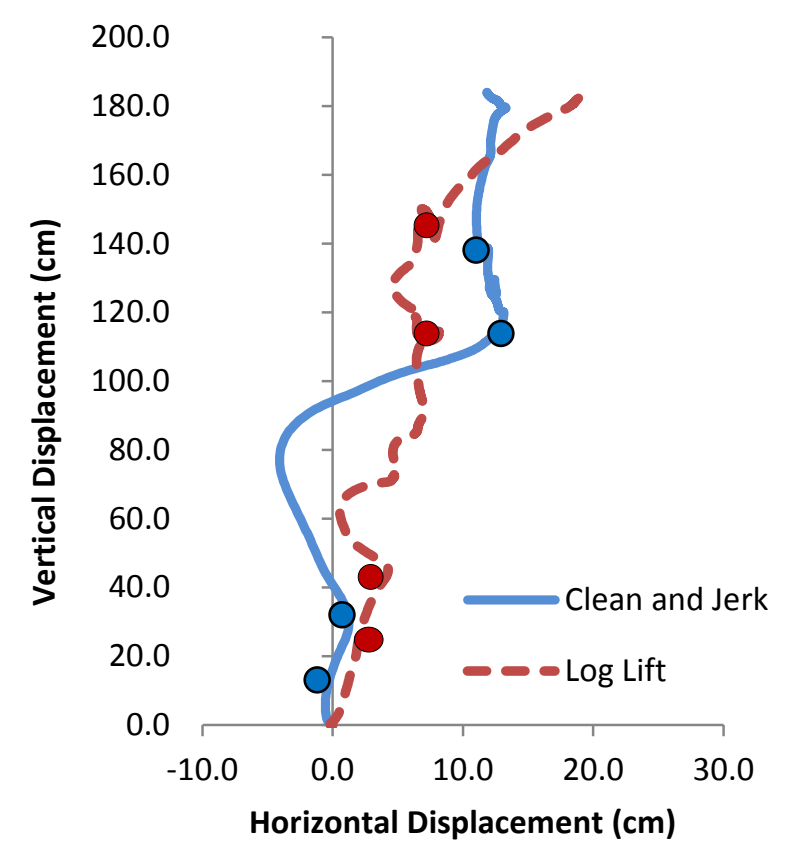

Figure 5: Group Mean Bar/Log Path Trajectories for the Clean and Jerk and Log Lift. Circles Indicate (from Bottom to Top) Top of First Pull, Middle of the Second Pull (At Maximum Point of Planterflexion), Top Retrieve and Bottom of the Dip and Drive. 

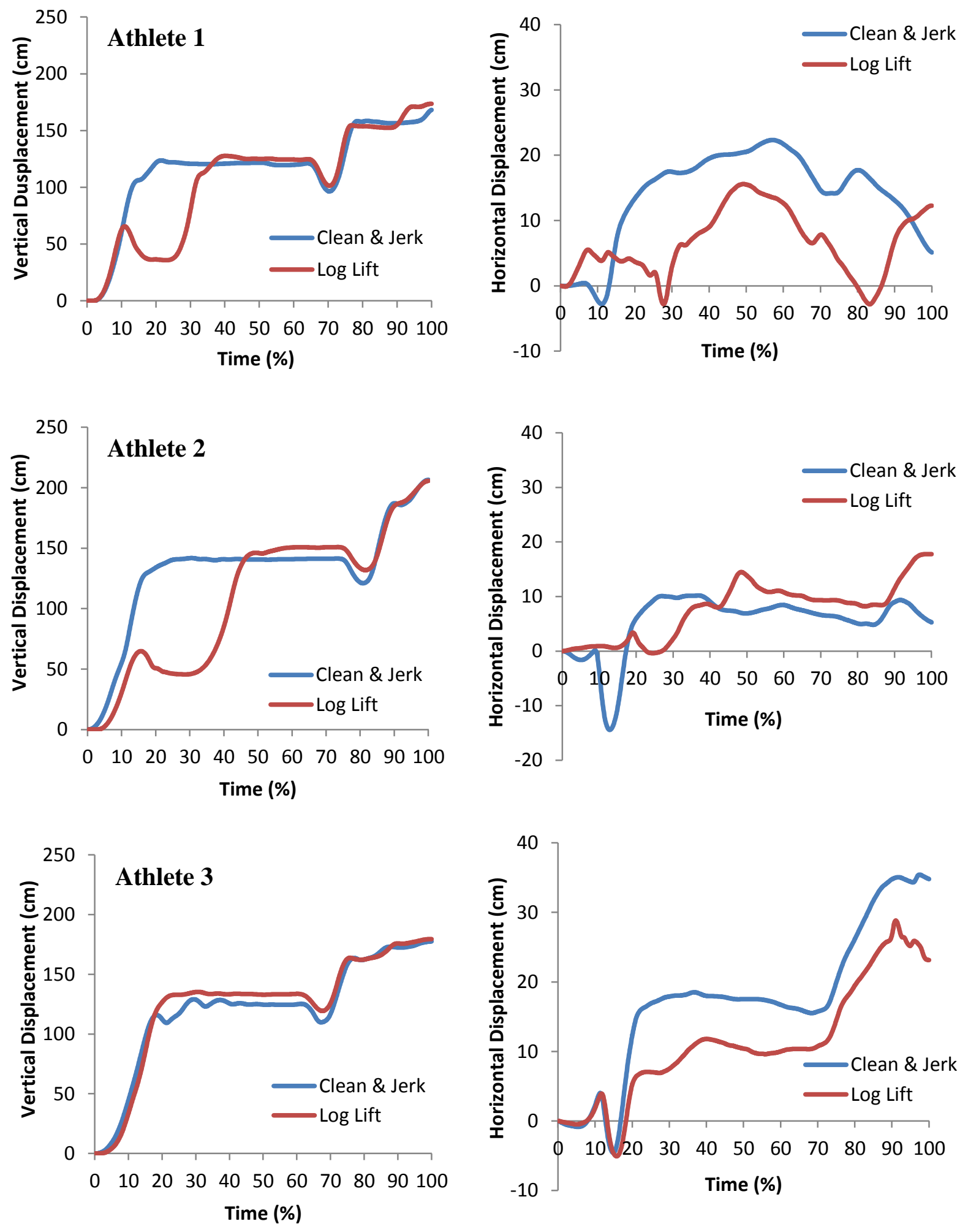

Figure 6: Pictorial representations of three log lifting techniques performed by strongman athletes. Vertical (left) and Horizontal (right) Displacements of the Bar Paths Normalised to 100\% of Mean Lift Time. Athlete 1: Log Lift with Jerk; Athlete 2: Log Lift with Push Jerk; Athlete 3: Log Lift and Jerk without Squat before Second Pull. 

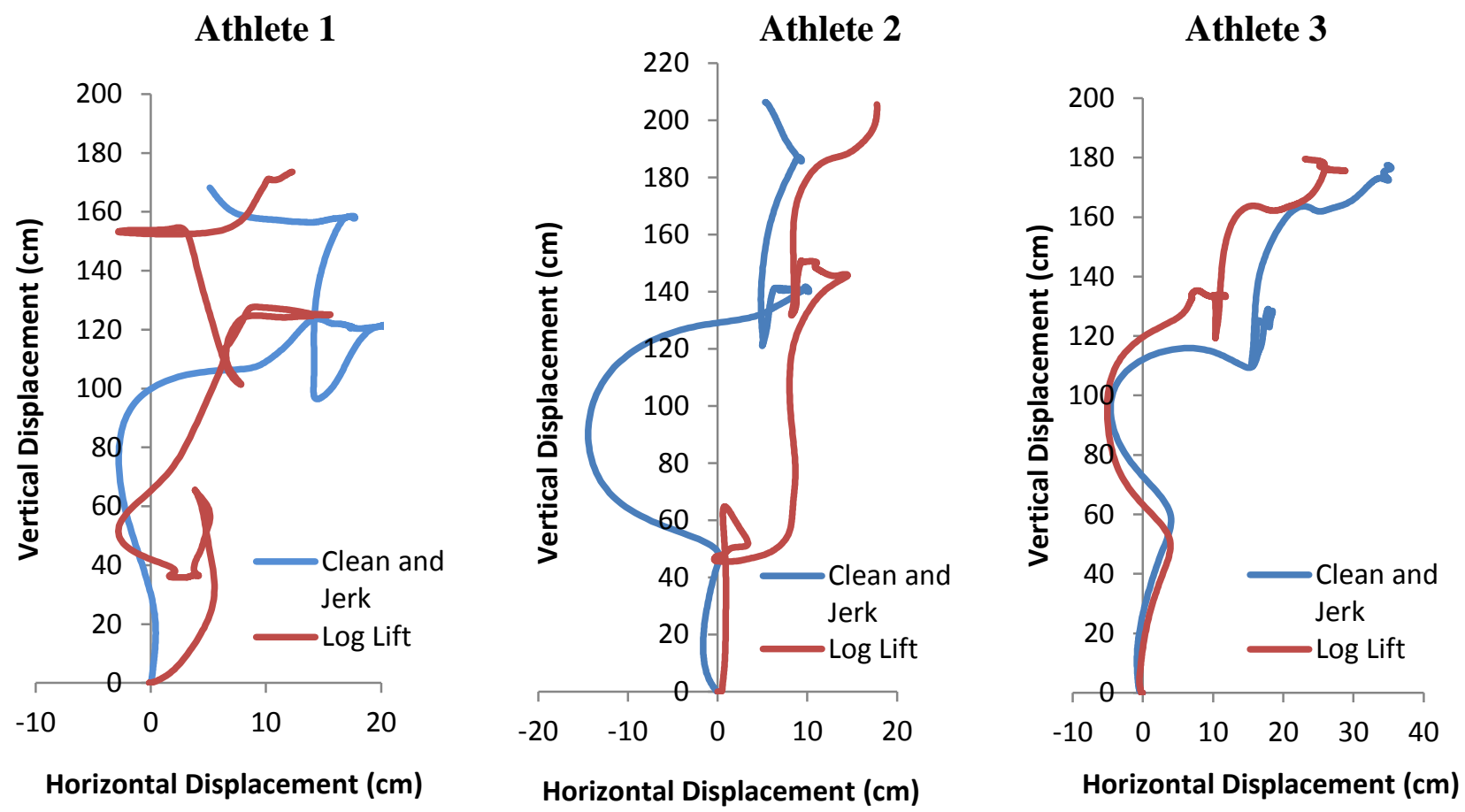

Figure 7: Pictorial Representations of Bar/Log Trajectories of the Three Log Lifting

Techniques Performed by Strongman Athletes. Athlete 1: Log Lift with Jerk; Athlete 2: Log Lift with Push Jerk; Athlete 3: Log Lift and Jerk without Squat before Second Pull. 